\title{
Scanning electron microscopical examination of gonococcal urethral exudate
}

\author{
RICHARD D. KLEIN ${ }^{1}$, IVAN L. ROTH, AND HOWARD S. MCCULLOUGH, JR \\ From the Department of Microbiology, University of Georgia, Athens, Georgia, USA
}

SUMMARY The relationship of gonococci and phagocytes in gonococcal urethral exudate was examined using a scanning electron microscope. Several stages in the phagocytic process were evident. These included pseudopodias, microvilli, and simple attachment of gonococci to phagocytic surfaces. Epithelial cells, also a part of the exudate, were examined in this study. Parallels are drawn between this and other phagocytic systems. The technique provides excellent preservation of phagocyte-bacterial interrelationships and offers a means of investigating the nature of the resistance of Neisseria gonorrhoeae to phagocytosis.

\section{Introduction}

Although the mechanism of the resistance of Neisseria gonorrhoeae to phagocytosis is not well understood, it has been proposed as a method of survival of $N$. gonorrhoeae in vivo (Thomas et al., 1973; Ofek et al., 1974). Until now, most studies on the resistance of the gonococcus to phagocytosis have used mouse (Thomas et al., 1973), rabbit and guinea-pig leucocytes (Thongthai and Sawyer, 1973). Human neutrophils (Dilworth et al., 1975; Swanson et al., 1975c), peripheral blood leucocytes (Punsalang and Sawyer, 1973; Ofek et al., 1974; Swanson et al., $1975 \mathrm{~b}$ ), and mouse peritoneal macrophages (Blake and Swanson, 1975) have also been used. Recently the presence of a leucocyte association factor has been reported (Swanson et al., 1975a,c). This nonpilar surface factor has been found to mediate the interaction between virulent gonococci and peripheral blood leucocytes in vitro (Blake and Swanson, 1975; Swanson et al., 1975c). These studies have helped to delineate the nature of gonococcal resistance in vitro. However, many of the phagocytic cells used in these studies are not present in the host at the site of infection. The interactions of gonococci and phagocytes in vivo largely remain unknown.

Investigation of the interaction of gonococci and phagocytes has mainly used the technique of thin

Address for reprints: Professor Ivan L. Roth, Department of Microbiology, University of Georgia, Athens, Georgia 30602, USA

iPresent address: Department of Microbiology, North Carolina State University, Raleigh, North Carolina 27607, USA

Received for publication 22 March 1976 sectioning (Ward et al., 1972; Ovčinnikov et al., 1974; Swanson and Zeligs, 1974). This technique however, allows only a two-dimensional means of investigation.

Scanning electron microscopical examination, which allows observation of a specimen in three dimensions, provides an excellent means of studying the topographical relationship between bacteria and phagocytes. One report has appeared in which the techniques of scanning electron microscopical examination and freeze etching were used to study gonococcal urethral exudate (Farzadegan and Roth, 1975), but the authors did not visualise gonococci on or near the surface of phagocytes.

The purpose of this study was to investigate the relationship that exists between gonococci and phagocytes under conditions as close to that of the site of infection as possible. This is accomplished by the observation of gonococcal urethral exudate. The discharge was handled as little as possible so as to preserve any geometrical relationships between phagocytes and gonococci that might exist.

\section{Materials and methods}

\section{SPECIMEN COLLECTION}

Urethral exudate was collected from a man with the classic symptoms of gonorrhoea (pain upon urination and urethral discharge) at the Athens-Clarke County Public Health Department, Athens, Georgia. A presumptive diagnosis of gonorrhoea was made with localisation of Gram-negative intracellular and/ or extracellular diplococci in a smear of the exudate. 
Confirmation of the diagnosis was made upon the isolation of Gram-negative, oxidase positive diplococci on Thayer-Martin with trimethoprim medium (Carr-Scarborough Microbiologicals Inc., Memphis, Tennessee). Only those exudates from which $N$. gonorrhoeae was isolated were used in this study.

\section{PREPARATION FOR SCANNING ELECTRON MICROSCOPY}

Urethral exudate specimens were prepared for the scanning electron microscopical examination by a modified technique of critical point drying (Anderson, 1951). Specimens fixed in $2 \%$ glutaraldehyde (Polysciences, Inc., Warrington, Pennsylvannia) in $0.1 \mathrm{~mol} / 1$ cacodylate buffer $\mathrm{pH} 7.0$ for four hours were deposited on $13 \mathrm{~mm}$ nuclepore GE-40 $0.4 \mu \mathrm{m}$ filters (General Electric Corporation, Pleasanton, California). The filters were held in a Swinny stainless steel adapter (Millipore Corporation, Bedford, Massachusetts) attached to a $2 \mathrm{ml}$ syringe. Dehydration was accomplished by passing a graded series of ethyl alcohol solutions through the filter $(70,80,95$, and $100 \%)$. Each ethyl alcohol solution was in contact with the filter for 15 minutes. After critical point drying the filter was metal coated with gold : palladium $(60: 40)$ in a Hummer II Sputter Coater (Technics Inc., Alexandria, Virginia) for two minutes. Observations were then made in a
Cambridge stereoscan mark 2A scanning electron microscope at an accelerating voltage of $8 \mathrm{kV}$.

\section{Results}

Fig. 1 shows the phagocytes of gonococcal urethral exudate; the extensively ruffled surface of the phagocyte can be seen. Gonococci are visible on the surface of a few less ruffled phagocytes. Most of the phagocytic cells seen in the urethral exudate were not extensively ruffled (Fig. 2). Microvilli are visible on the surface of these cells which lack the undulating membranes of other phagocytes. Extensive debris is often seen associated with the phagocytes (Fig. 3), and gonococci are associated with the debris. Pseudopods are visible on the surface of the smoother phagocytes (Fig. 4). The pseudopod in Fig. 4 shows direct contact between the membrane of the phagocyte and the surface of the gonococcus.

Many phagocytes in the exudate displayed large rotund protuberances on their surfaces (Fig. 5). These protuberances varied in size between cells and always appeared on cells which were devoid of membranous ruffles. Many gonococci were seen on the surfaces of the phagocytic cells (Figs 1, 3, and 6). These gonococcal cells appear to be attached to the surface of the phagocyte but are not in the process of ingestion. Gonococci which appear to be

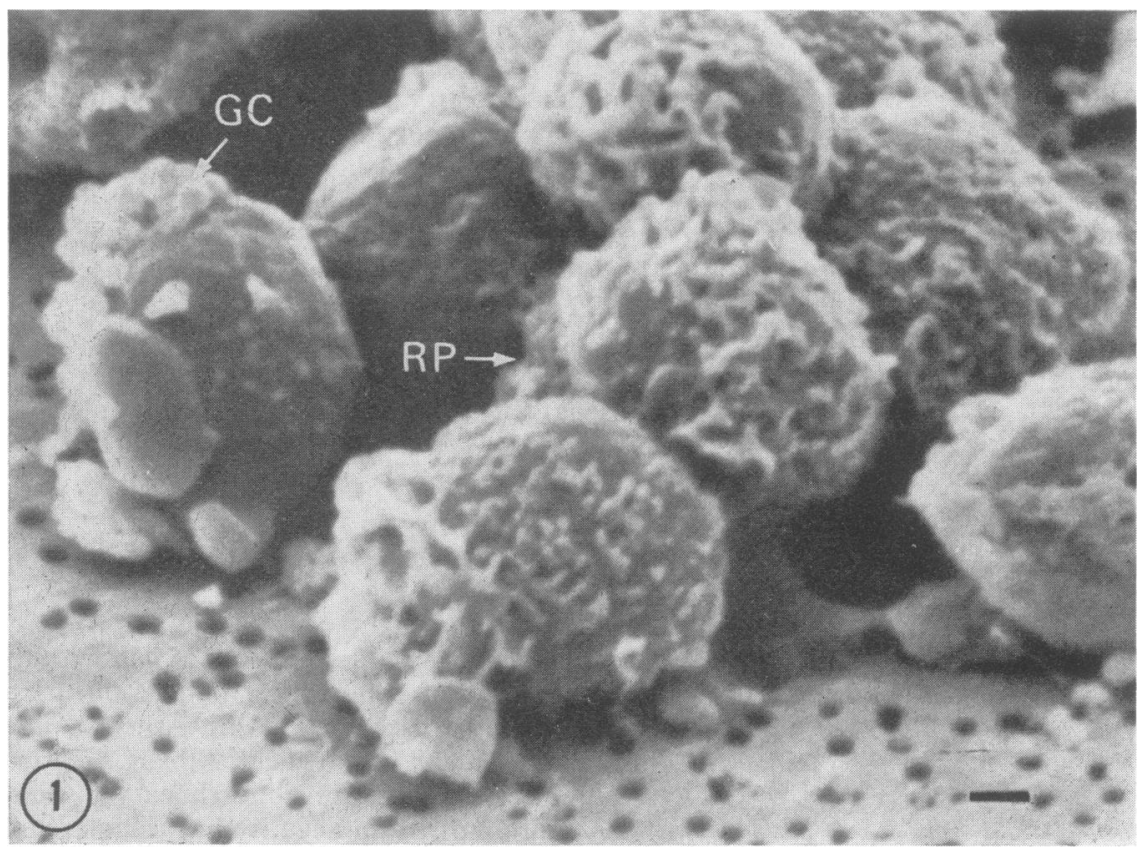

Fig. 1 (RP) Ruffled phagocytes, $(G C)$ gonococci on smooth phagocyte. Bar equals $1 \mu m$. 


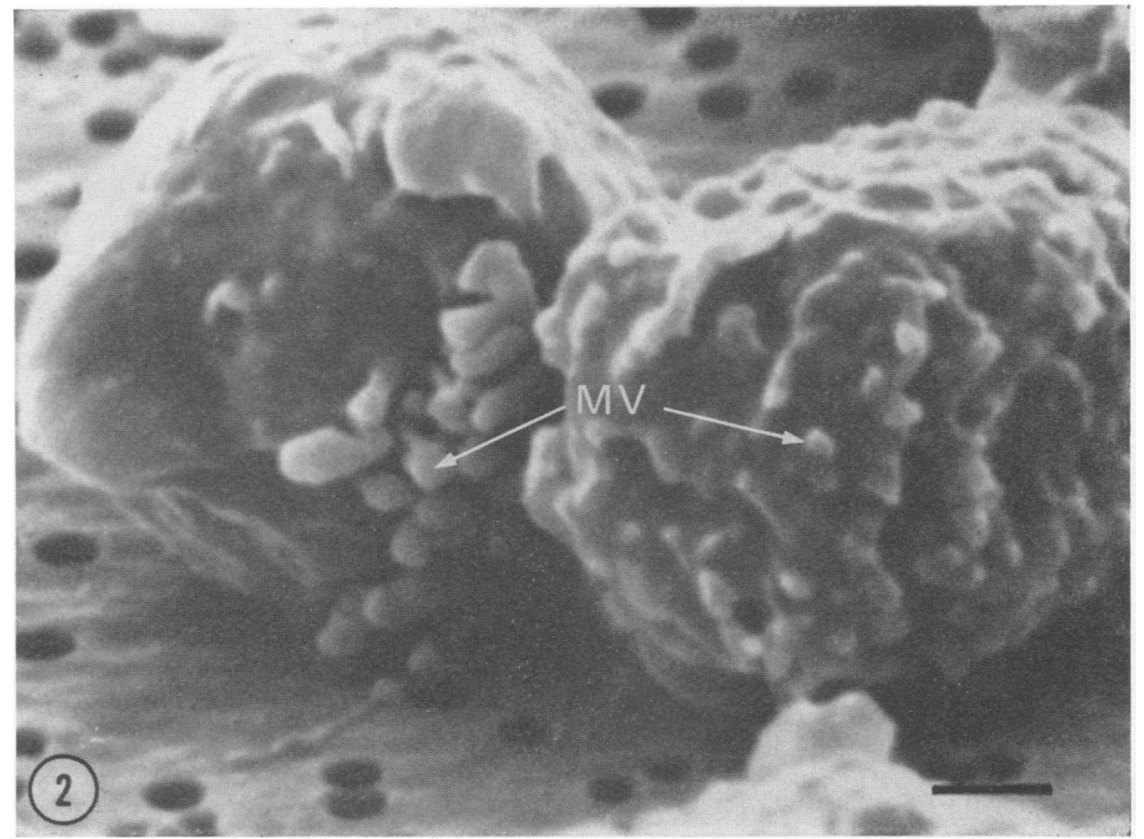

Fig. 2 Surface of smoother phagocytes with microvilli $(M V)$. Bar equals $1 \mu m$.

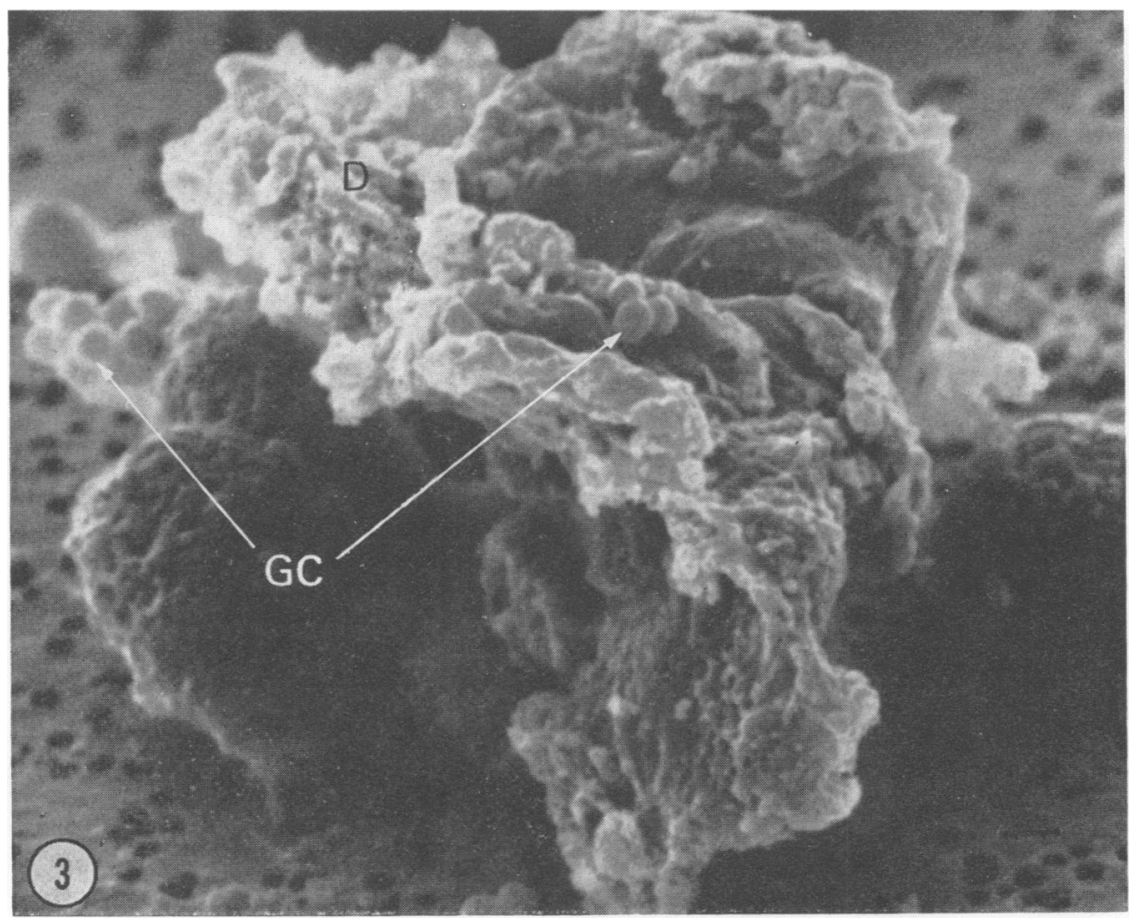

Fig. 3 Debris (D) associated with phagocytes, $(G C)$ gonococci. Bar equals $1 \mu m$. 


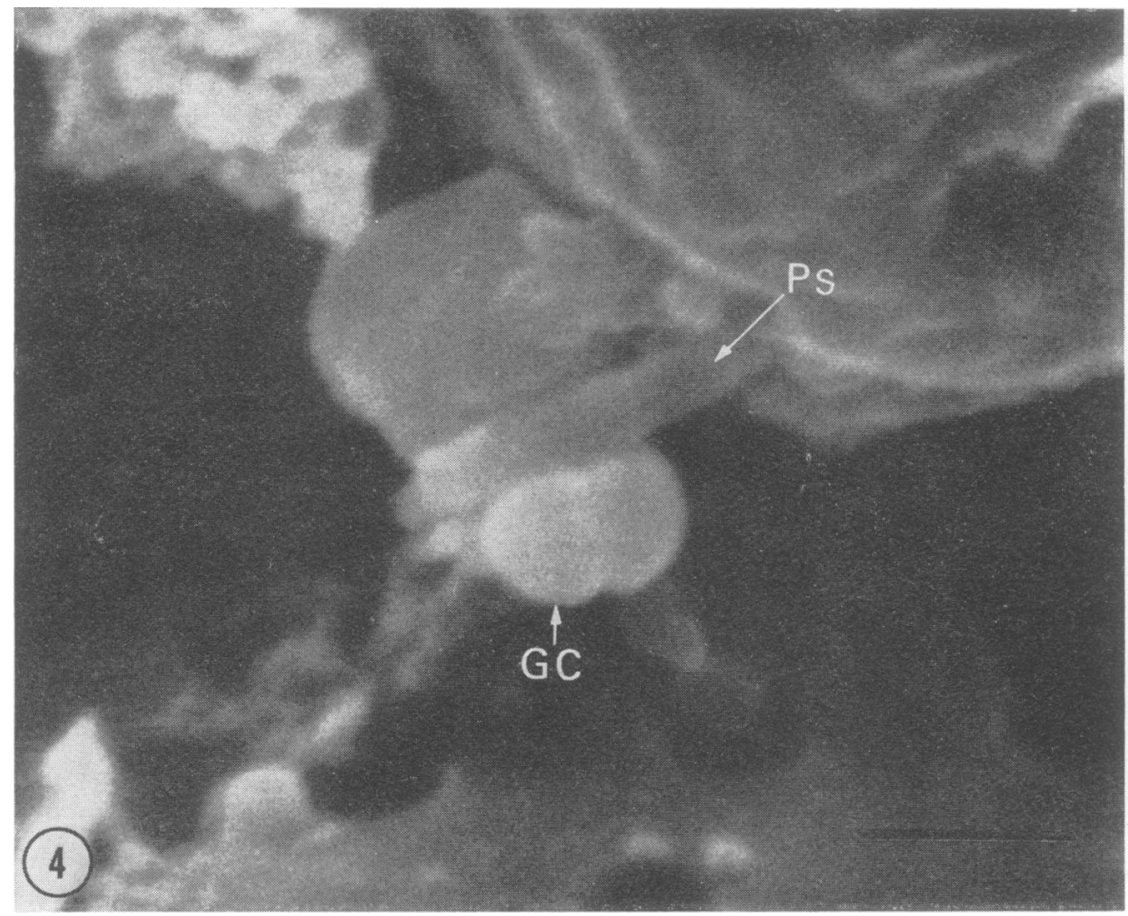

Fig. 4 High magnification of pseudopod (Ps) and gonococcus (GC). Bar equals $1 \mu \mathrm{m}$.

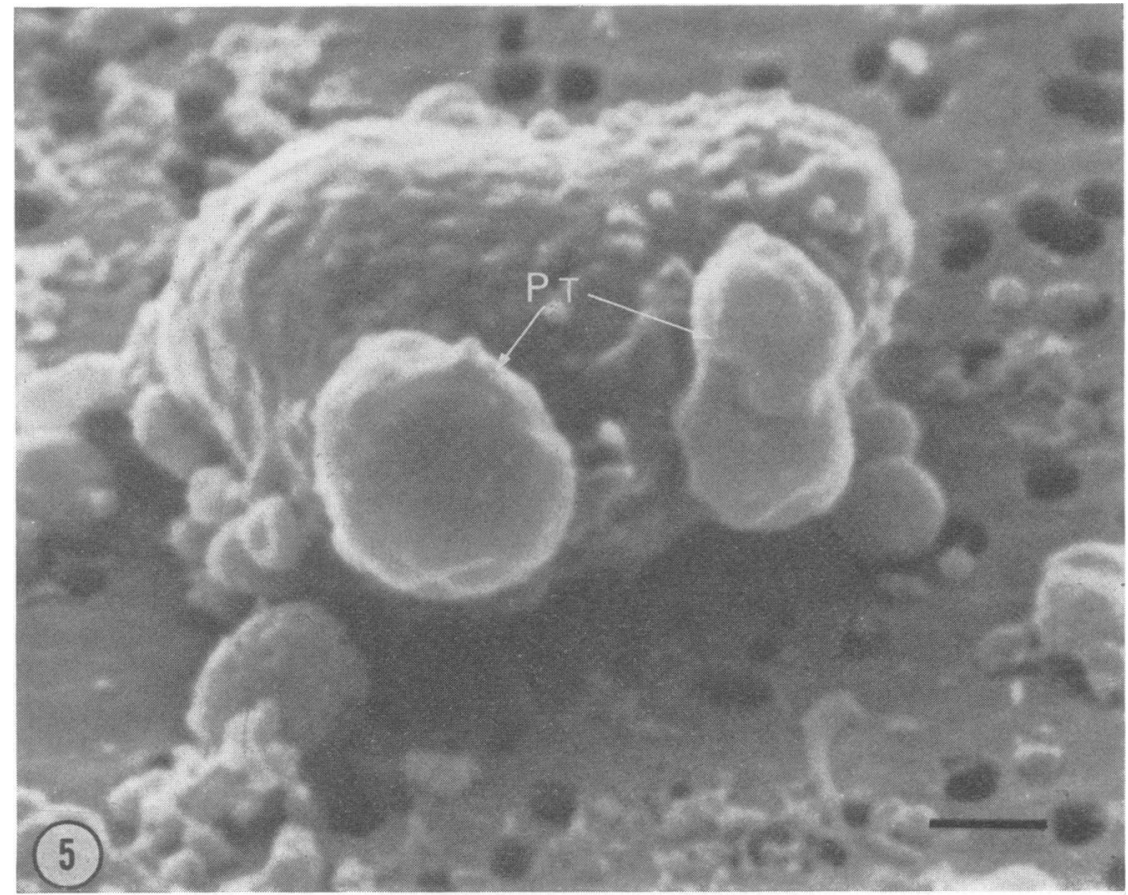

Fig. 5 Phagocyte with spherical protuberances (PT). Bar equals $1 \mu \mathrm{m}$. 


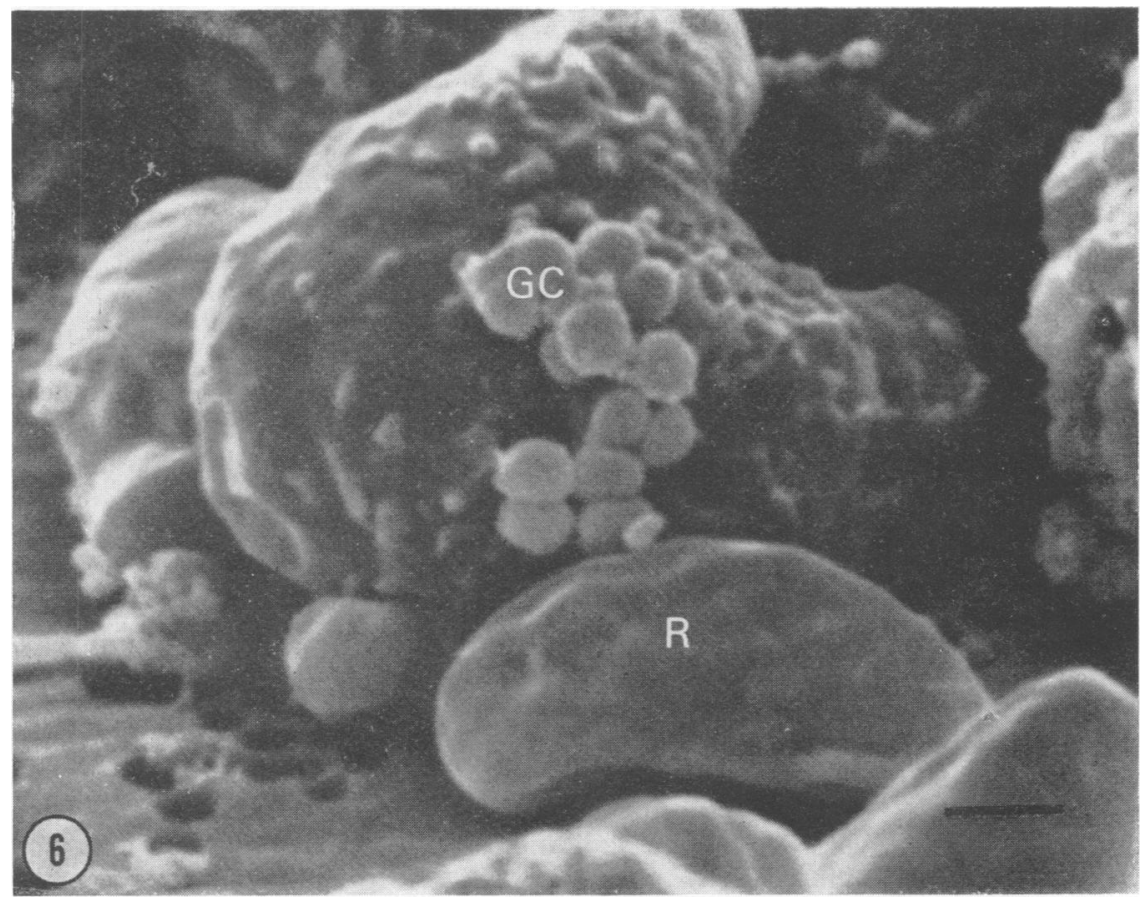

Fig. 6 Gonococci $(G C)$ on phagocyte surface, red blood cell $(R)$. Bar equals $1 \mu \mathrm{m}$.

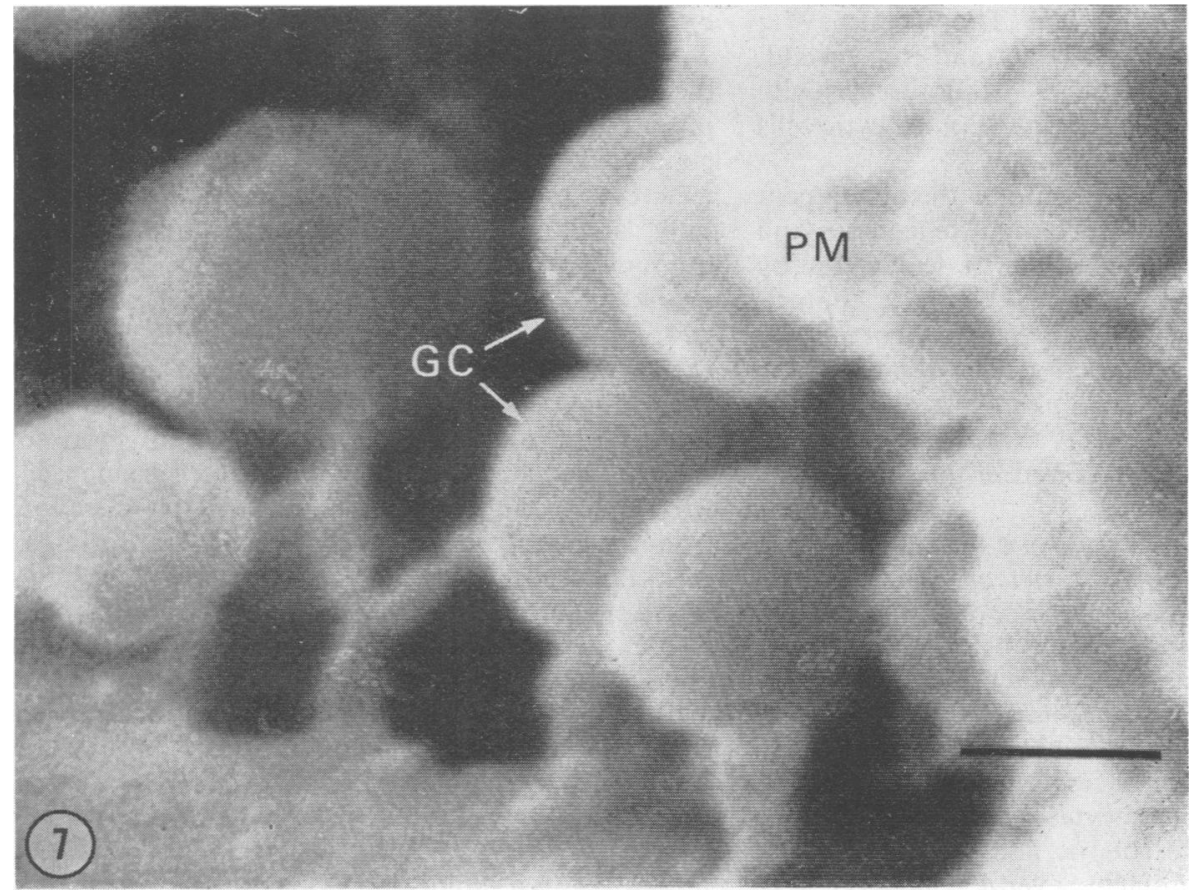

Fig. 7 Gonococci $(G C)$ intimately attached to phagocyte membrane $(P M)$. Bar equals $0.5 \mu m$. 
in the process of ingestion are seen in Figs 7 and 8. A gonococcus in Fig. 7 appears to be attached to the surface of the phagocyte. Another gonococcus is seen in contact with the phagocytic membrane in Fig. 8.

Gonococci not in contact with the phagocyte surface were also present in the exudate (Fig. 9). These diplococci appeared to adhere to one another and were not in contact with a phagocytic cell. An epithelial cell is seen in Fig. 10. Several phagocytes are visible around the periphery of the cell. In some cases the membrane of the epithelial cell is found covering the surface of the phagocyte. Diplococci are present on the surface of two phagocytes. A higher magnification of the rough surface of the epithelial cell is shown in Fig. 11.

\section{Discussion}

In several studies of phagocytosis, the wrinkled nature of the phagocyte surface has been noted (Warfel and Elberg, 1970; Goodall and Thompson, 1971; Klainer and Betsch, 1973; Warfel et al., 1973; Klainer and Rectenwald, 1974; Farzadegan and Roth, 1975); this characteristic appears to be a common phenomenon of phagocytic cells. Warfel et al. (1973) reported the presence of microvilli on the surface of peritoneal macrophages during the attachment of Brucella melitensis. The presence of pseudopods on phagocytes has been reported by various authors (Goodall and Thompson, 1971; Klainer and Betsch, 1973; Klainer and Rectenwald, 1974; Swanson and Zeligs, 1974). Both microvilli and pseudopods were present on the phagocytic cells of the gonococcal urethral exudate.

Klainer and Betsch (1973) studied the attachment of Staphylococcus aureus to human leucocytes and noted that cocci were attached to leucocytes by means of pseudopods or simple surface contact. Swanson and Zeligs (1974), in the study of phagocytosis of gonococci by human leucocytes, noted the attachment of the bacteria to phagocytes by pseudopods and by surface contact. Both these means of phagocytosis have been observed in this study (Figs 7 and 8).

In the study of the phagocytosis of latex beads by the amoeba Acanthamoeba castellanii (Goodall and Thompson, 1971) phagocytosis was observed to occur by means of filopodia and by surface contact. When a latex bead came in contact with the amoeba the wrinkled surface was found to surround and engulf it. The bulges resulting from this process are similar to the protuberances found on the surface of some exudate phagocytes (Fig. 5). The protuberances may represent the final stage in phagocytosis by surface contact. Several gonococci were found in this study to be partially surrounded by the phagocytic membrane (Figs 8 and 9). These cells may be in a stage of ingestion.

Changes in the phagocytic cell surface topography during phagocytosis have not been thoroughly investigated. Studies on the phagocytosis of Escherichia coli and $S$. aureus by mouse peritoneal macrophages (Klainer and Rectenwald, 1974) have revealed that macrophages which were not challenged by the presence of bacteria had membranes with few ruffles or microvilli. When bacteria were introduced to macrophage preparations a sharp increase in the number of microvilli in each cell was noted. Membrane synthesis may be accelerated as a result of this challenge by bacteria. Phagocytic cells ingesting bacteria undergo a sudden increase in the total cell volume. At the same time surface membrane is lost to form phagosomes. While it is true that these cells do have dynamic membranes it seems logical to assume that as the loss of surface membrane continues and total cell volume increases, de novo membrane synthesis may not be able to replace the amount of surface membrane lost to phagosomes. The cellular surface would then become progressively smoother as phagocytosis continued. When this point of membrane limitation is reached it would be necessary for the phagocytic cell to synthesise surface membrane before phagocytosis could continue. As phagocytosis progressed the phagocyte surface would become increasingly less ruffled. This is supported by the studies of phagocytosis of latex beads by A. castellanii (Goodall and Thompson, 1971), where the convolutions of the amoeboid surface became progressively shallower as the phagocytic process continued. The changes in the topography of phagocytic cells during phagocytosis have not been carefully analysed. Scanning electron microscopical examination is well suited to the study of this problem.

The infection of the male with virulent $N$. gonorrhoeae elicits the classical symptoms of gonorrhoea (pain upon urination and urethral discharge). The resulting purulent exudate comprises polymorphonuclear leucocytes, lymphocytes, and plasma cells which have migrated to the site of the infection. Columnar epithelial cells which have been dislodged from the urethra may also be present. Thin sections of epithelial cells removed from the urethra by gentle scraping have revealed the attachment of gonococci to urethral epithelial cells (Ward and Watt, 1972). The rough nature of the epithelial cell surface (Figs 10 and 11) would provide an excellent site for the attachment of gonococci. No gonococci were found on the surface of the epithelial cells in this study, but they might have been removed during processing. An interesting observation of this study was the presence of phagocytes intimately associated 


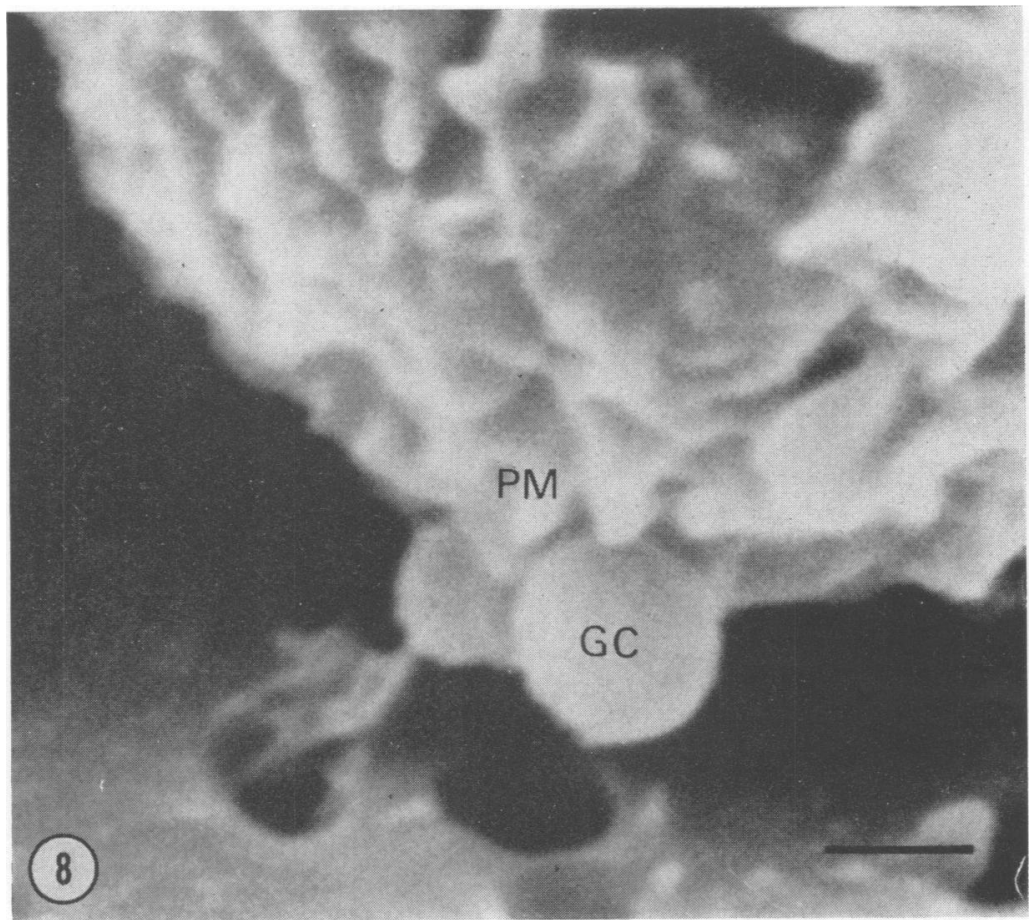

Fig. 8 Phagocytic membrane $(P M)$ partially enclosing $a$ gonoccus $(G C)$. Bar equals $0.5 \mu \mathrm{m}$.

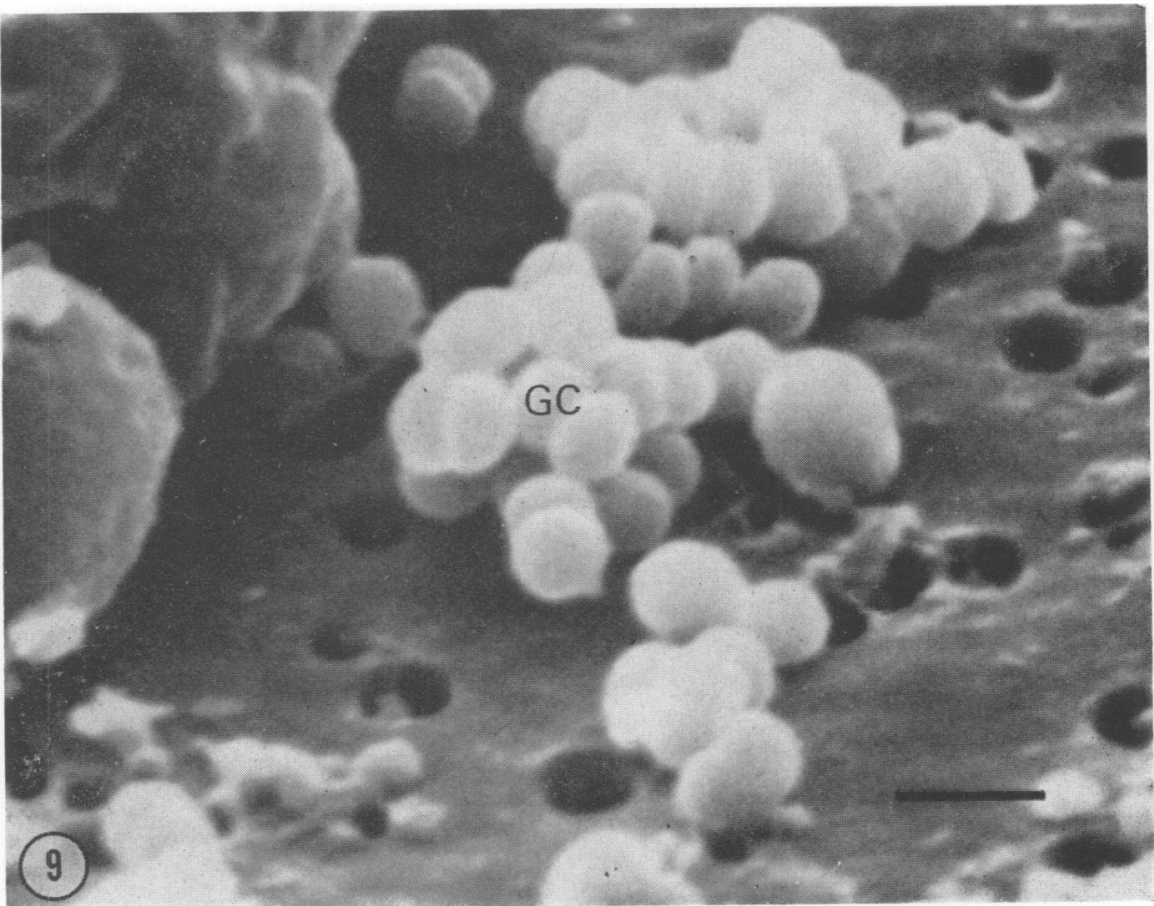

Fig. 9 Gonococci $(G C)$ not associated with a phagocyte. Bar equals $1 \mu \mathrm{m}$. 


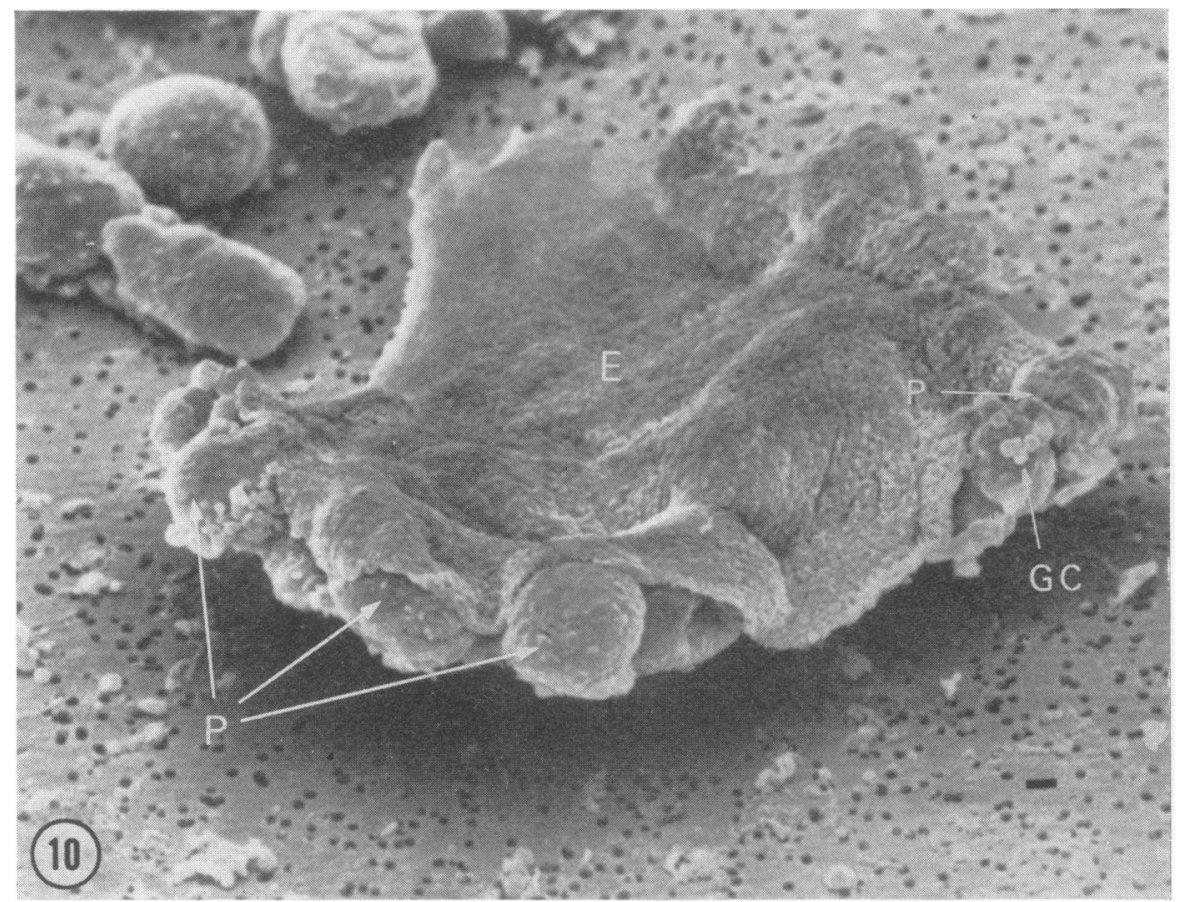

Fig. 10 Epithelial cell $(E)$ with surrounding phagocytes $(P)$, gonococci $(G C)$. Bar equals $1 \mu m$.

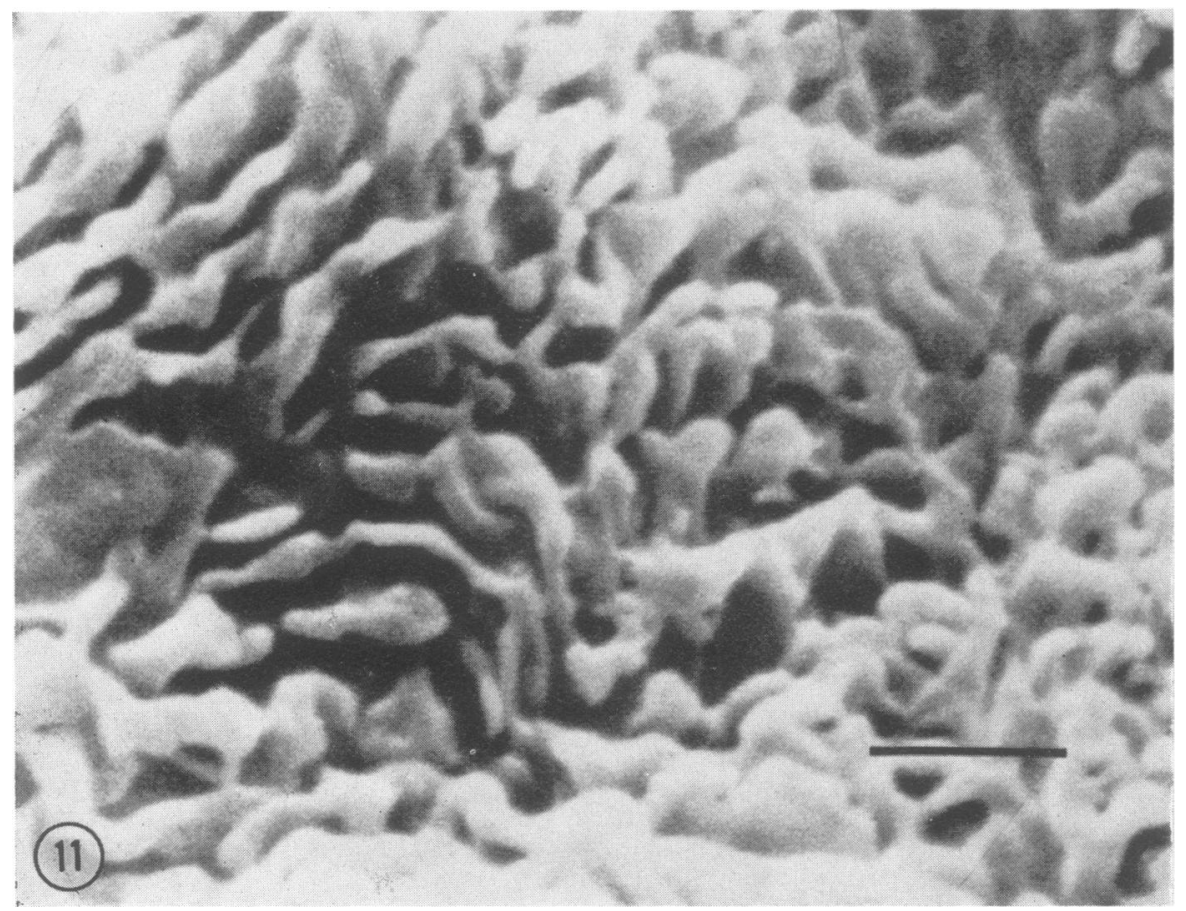

Fig. 11 High magnification of the rough surface of an epithelial cell. Bar equals $1 \mu \mathrm{m}$. 
with the epithelial cells (Fig. 10). Some phagocytes appear to be partially covered by the epithelial cell membrane. If gonococci were to attach to the epithelial cells at the periphery, leucocytes migrating between the columnar cells could attempt to phagocytise the attached bacteria. Thus the phagocytes could become attached to the epithelial cells. This process could then be a factor in the dislodgement of epithelial cells from the lumen of the urinary tract during the course of the disease.

The debris present in and around the phagocytes (Fig. 3) always appeared in association with gonococci, but its exact nature is not known. It may represent the distortion of the exudate mucus caused by ethanol dehydration and/or critical point drying. If this material proves to be mucus then gonococci would seem to spread through the exudate in it. The possibility also exists that the debris might be the extruded material of the phagosomes.

The means by which gonococci are rendered resistant to phagocytosis are not known. These bacterial cells may prove to be resistant to ingestion by the phagocytes, to degradation by the phagocytic enzymes, or both. In the study of the attachment and ingestion phases of the phagocytic process, Rabinovitch (1967) noted the discrete nature of these stages. Attachment of glutaraldehyde-fixed red blood cells (RBCs) to macrophage surfaces was linear with the number of RBCs present. The presence of serum or divalent cations was not required. In contrast the ingestion phase of phagocytosis was not linear with increasing RBC numbers and actually decreased. A constant percentage (2-5) of RBCs was ingested. Serum and divalent cations were required for this process. In this study large numbers of bacteria were seen attached to phagocyte surfaces (Figs 1 and 6). In comparison only a small number were seen in the process of ingestion (Figs 7 and 8). As the mucus and host cells which form the exudate accumulate in the lumen of the urinary tract the absence of serum or divalent cations may play a role in the ingestion of gonococci.

Several stages in the phagocytic process of $N$. gonorrhoeae are presented here. However their relationship to the overall process is not understood. Gonococci have been demonstrated here to be phagocytised by the methods of surface contact and pseudopods. This confirms earlier studies of the phagocytosis of gonococci in vitro. Phagocytes have also been demonstrated to interact with epithelial cells. This report has demonstrated that the techniques involved provide excellent preservation of bacterial-phagocyte interrelationships. The examination of gonococcal phagocyte mixtures, specifically urethral exudate by this method is readily suited to the elucidation of the resistance of $N$. gonorrhoeae to phagocytosis and the process of phagocytosis itself. Further studies of this nature are now in progress.

\section{References}

Anderson, T. F. (1951). Techniques for preservation of 3-dimensional structure in preparing specimens for electron microscope. Transactions of the New York Academy of Sciences, 13, 130-134.

Blake, M., and Swanson, J. (1975). Studies on gonococcus infection. IX. In vitro decreased association of pilated gonococci with mouse peritoneal macrophages. Infection and Immunity, 11, 1402-1404.

Dilworth, J. A., Hendley, J. O., and Mandell, G. L. (1975). Attachment and ingestion of gonococci human neutrophils. Infection and Immunity, 11, 512-516.

Farzadegan, H., and Roth, I. L. (1975). Scanning electron microscopy and freeze-etching of gonorrhoeal urethral exudate. Brirish Journal of Venereal Diseases, 51, 83-91.

Goodall, R. J., and Thompson, J. E. (1971). A scanning electron microscopic study of phagocytosis. Experimental Cell Research, 64, 1-8.

Klainer, A. S., and Betsch, C. S. (1973). Scanning electron microscopy of the attachment of polymorphonuclear leukocytes to Staphylococcus aureus. Journal of Infectious Diseases, 127, 686-688.

Klainer, A. S., and Rectenwald, M. (1974). Sranning Electron Microscopy. Edited by O. Johari and I. Corvin, p. 822. Illinois Institute of Technology Research Institute: Chicago.

Ofek, I., Beachey, E. H., and Bisno, A. L. (1974). Resistance of Neisseria gonorrhoeae to phagocytosis: relationship to colonial morphology and surface pili. Journal of Infectious Diseases, 129, 310-316.

Ovčinnikov, N. M., Delektorskij, V. V., and Afanas'ev, B. A. (1974). Electron microscopy of gonococci in the urethral secretions of patients with gonorrhoea treated with penicillin and erythromycin. British Journal of Venereal Diseases, 50, 179-194.

Punsalang, A. P., and Sawyer, W. D. (1973). Role of pili in the virulence of Neisseria gonorrhoeae. Infection and Immunity, 8, 255-263.

Rabinovitch, M. (1967). The dissociation of the attachment and ingestion phases of phagocytosis by macrophages. Experimental Cell Research, 46, 19-28.

Swanson, J., King, G., and Zeligs, B. (1975a). Studies on gonococcus infection. VII. In vitro killing of gonococci by human leukocytes. Infection and Immunity, 11, 65-68.

Swanson, J., King, G., and Zeligs, B. (1975b). Studies on gonococcus infection. VIII. 125 Iodine labeling of gonococci and studies on their in vitro interactions with eukaryotic cells. Infection and Immunity, 11, 453-459.

Swanson, J., Sparks, E., Young, D., and King, G. (1975c). Studies on gonococcus infection. $\mathrm{X}$. Pili and leukocyte association factor as mediators of interactions between gonococci and eukaryotic cells in vitro. Infection and Immunity, 11, 1352-1361.

Swanson, J., and Zeligs, B. (1974). Studies on gonococcus infection. VI. Electron microscopic study on in vitro phagocytosis of gonococci by human leukocytes. Infection and Immunity, 10, 645-656.

Thomas, D. W.. Hill, J. C., and Tyeryar, F. J. (1973). Interaction of gonococci with phagocytic leukocytes from men and mice. Infection and Immunity, 8, 98-104.

Thongthai, C., and Sawyer, W. D. (1973). Studies on the virulence of Neisseria gonorrhoeae. I. Relation of colonial morphology and resistance to phagocytosis by polymorphonuclear leukocytes. Infection and Immunity, 7, 373-379.

Ward, M. E., Glynn, A. A., and Watt, P. J. (1972). The fate of gonococci in polymorphonuclear leucocytes: an electron microscopic study of the natural disease. British Journal of Experimental Pathology, 53, 289-294.

Ward, M. E., and Watt, P. J. (1972). Adherence of Neisseria gonorrhoeae to urethral mucosal cells: an electron-microscopic study of human gonorrhea. Journal of Infectious Diseases, 126, 601-605.

Warfel, A. H., and Elberg, S. S. (1970). Macrophage membranes viewed through a scanning electron microscope. Science, 170, 446-447.

Warfel, A. H., Elberg, S. S., and Hayes, T. L. (1973). Surface morphology of peritoneal macrophages during the attachment of Brucella melitensis. Infection and Immunity, 8, 665-668. 